\title{
Frente el autoritarismo,la creación. La experiencia de AIDA y su relectura en el film El Exilio de Gardel (Fernando Solanas, Francia /Argentina, 1985)
}

\section{Cristiá, Moira}

Resumen: En octubre de 1979, un grupo de artistas e intelectuales franceses y extranjeros encabezados por la directora de teatro Ariane Mnouchkine crearon AIDA

(Association internationale de défense des artistes victimes de la répression dans le monde), con el objetivo de denunciar la censura y las violaciones de Derechos Humanos de artistas en distintos países. La asociación proponía acciones creativas, de manera de ejercer presión internacional sobre los regímenes victimarios. Fundada en París, AIDA se desplegó por varias ciudades francesas, por otros países europeos y en Estados Unidos, empleando las redes de contactos de los miembros para articular acciones. El caso de la represión de la dictadura argentina

Cuadernos del Centro de Estudios de Diseño y Comunicación Nº 68

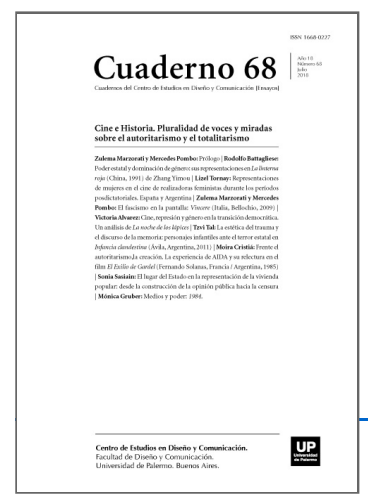

ISSN: 1668-0227

Cine e Historia.

Pluralidad de voces y

miradas sobre el

autoritarismo y el

totalitarismo

Año XVIII, Julio 2018, Buenos Aires, Argentina | 148 páginas

descargar PDF ver índice de la publicación

Ver todos los libros de la publicación

compartir en Facebook mereció una importante campaña de repudio, potenciada por la presencia de algunos exiliados argentinos en el comité ejecutivo de la asociación. Bajo el título "Cien artistas argentinos desaparecidos" se coordinaron una serie de manifestaciones de solidaridad en distintas ciudades que incluyeron marchas, elaboración de pinturas y postales, así como de un libro sobre la represión cultural en Argentina publicado en París y, poco después, en Madrid.

La mayor manifestación de AIDA de esta campaña, una particular marcha realizada en París el 14 de noviembre de 1981, fue filmada, entre otros, por el cineasta argentino Fernando Solanas, miembro activo de la asociación. La experiencia del exilio, y de la AIDA en particular, aparecen como materia prima de su film de ficción El Exilio de Gardel (1985), así como las imágenes capturadas en aquella jornada son incorporadas a las rodadas para el film. Sustentado en archivos poco explorados (documentos escritos y visuales, correspondencia), prensa y entrevistas, este artículo intentará delinear la acción realizada por AIDA y analizar la manera en la que Fernando Solanas construyó su obra reelaborando la memoria de su experiencia en la asociación. El estudio de esta película permitirá colaborar, a partir de un análisis empírico, a la reflexión y teorización sobre la función de la creación como espacio de resistencia, de acción en la esfera pública transnacional y de memoria de experiencias vitalespersonales y colectivas. 
Palabras clave: solidaridad internacional - historia transnacional - exilio - artistas - Derechos Humanos - El Exilio de Gardel

(*) Posdoc CONICET (IIGG) Colaboradora científica del Institut d'Histoire du Temps Pré- sent (Francia). Responsable de la sección "Imágenes, memoria y sonido" y miembro del comité editorial de la revista Nuevo Mundo Mundos Nuevos. Coordinación de dossier sobre Cine 2010 dossier «Cine, identidades e Historia en América Latina» con Tzvi Tal (Sapir Academic College, Israel), Nuevo Mundo Mundos Nuevos, $n^{\circ} 10$, EHESS.

\section{Introducción}

En julio de 1979, la directora de teatro Ariane Mnouchkine y el cineasta Claude Lelouch brindaron una conferencia de prensa en París sobre la crítica situación de la cultura en el Cono Sur. Tras una gira motivada por su preocupación por los actores de Teatro Aleph de Chile, los franceses denunciaron la censura, represión de artistas y listas negras en aquella región, afirmando contundentemente que "se mata gente desde adentro" al imposibilitar la creación1. Meses después, en diciembre de ese año, dichos intelectuales publicarían en el diario Le Monde el manifiesto fundacional de una asociación, bajo el título "La Libertad es como una piel de zapa"2 . Allí denunciaban los abusos estatales en distintos países y expresaban su voluntad de defender la libertad de creación artística en todo el mundo. Los firmantes aclaraban que "los artistas perseguidos son sólo la parte visible de un siniestro y gigantesco iceberg" 3 . Conformada en octubre, AIDA (Asociación Internacional de Defensa de Artistas Víctimas de la Represión en el Mundo) tomó personalidad jurídica el 3 de diciembre de 1979, cuando fue inscripta como asociación civil en la Prefectura de París4 . Poco después la asociación alquiló un local en el subsuelo de un edificio5, de manera de cobrar mayor autonomía respecto a la compañía de Mnouchkine, el Théâtre du Soleil, cuyas instalaciones la albergaron en sus inicios.

El objetivo de AIDA sería repudiar la censura y represión de la cultura a través de manifestaciones en las que el arte fuera la herramienta para la denuncia, combatiendo la violencia con imaginación y más creación. El logo de la asociación -circular, con una franja cruzada y de color rojo-, evoca a los típicos sellos de censura, pero en este caso invirtiendo su sentido. La intención era usar los medios propios a los artistas para sacar a la luz aquello que se silenciaba y así defender casos concretos de artistas censurados. En uno de los documentos de difusión de AIDA se señalaba como una feliz coincidencia, que encarnaba su vocación creativa, que su sigla recordara a la ópera de Verdi de 1871. Asimismo, en su presentación en un volante de 1981, se subrayaba con gran énfasis el repudio de que artistas de diferentes latitudes sufrieran represión:

(...) por expresar sus ideas, porque relatan hechos reales. Los artistas, ya sean escritores, cineastas, músicos o pintores, fotógrafos o escultores, son intimidados, censurados, prohibidos, encerrados, encarcelados, torturados, asesinados en países donde la razón de Estado prohíbe toda crítica, toda libertad de expresión o de opinión, donde ella sirve de argumento en ausencia de prueba (...) (Volante, Cent bannières dans Paris pour cent artistes disparus en Argentine 1981, Archivos AIDA, La Cartoucherie, París)

En consecuencia, AIDA se proponía "romper el silencio que rodea la represión, defendiendo la libertad de expresión, creación y trabajo de los artistas, en cualquier lugar del mundo en el que ésta se encuentre amenazada" (Idem). La asociación se expandió por seis países -Francia, Alemania, Suiza, Holanda, Bélgica y Estados Unidos-, con características particulares en cada uno, pero cuyos comités se coordinaban en reuniones regulares. Así AIDA se constituyó como una red de solidaridad en la que exiliados y locales trabajaban conjuntamente desde distintas latitudes para ejercer presión frente a los gobiernos nacionales que censuraban la creación considerada subversiva.

El caso de la violencia política en Argentina motivó una importante campaña que adoptó diversas formas en las distintas sedes de la asociación, complementando la denuncia pública con la solidaridad hacia los afectados. La manifestación de más impacto de dicha campaña, la marcha realizada en París el 14 de noviembre de 1981, fue filmada, entre otros, por Fernando Solanas, miembro activo del comité de París. La experiencia del exilio, y de AIDA en particular, aparece como materia prima de su film de ficción El Exilio de Gardel (1985). Además de anécdotas, debates y emociones de esos tiempos, algunas imágenes capturadas en aquella jornada por el cineasta argentino fueron integradas con otras rodadas especialmente para el film. En este artículo se intentará delinear y analizar la manera en la que Fernando Solanas construyó su obra como una reelaboración de los tiempos del exilio y de la acción de AIDA. El estudio de esta película apuntará a demostrar que la creación funcionó como espacio de resistencia, de acción en la esfera pública transnacional y de memoria de experiencias vitales personales y colectivas tanto traumáticas como reparadoras.

Con ese fin, se estudiará en primer lugar las características generales de la campaña organizada por dicha asociación para denunciar la desaparición de artistas argentinos, evidenciando la manera en la que actuaban en la esfera pública transnacional (Fraser, 2014)6. Se cruzarán fuentes periodísticas, documentos escritos, registros visuales y testimonios orales para intentar reconstruir las características de la actividad solidaria dinamizada por esta asociación respecto al caso argentino a partir de comités en distintos puntos de los países centrales7 . En segundo lugar, se analizará el film realizado por Solanas, y en cuya producción ejecutiva también participaba otro de los miembros de AIDA, el reconocido militante peronista Envar el Kadri. Centraremosla atención principalmente en la manera en la que se incorporó la memoria de la experiencia asociativa en la 
ficción. Finalmente, se aportará una reflexión sobre este uso de la memoria personal y colectiva en la construcción de dicha película, reelaborando los recuerdos desde el presente.

\section{AIDA y su campaña por Argentina}

De manera similar a Amnesty international, AIDA actuaba principalmente adoptando casos específicosde artistas por los cuales estimaba poder obtener resultados reales. Para ello, organizaba tanto acciones informativas como otras "espectaculares"8, destinadas a llamar la atención del público local sobre la represión en diferentes países. Como el viaje de Mnouchkine y Lelouch al Cono Sur, AIDA también se proponía el envío de delegaciones de artistas a los países en donde existían acusaciones de represión a la actividad creativa para relevar información de primera mano9. Aunque la asociación se interesaba por casos de diferentes horizontes (incluyendo Europa del Este, países africanos y asiáticos), es innegable que su significativo interés por América Latina se alimentó de la importante recepción de exiliados de esa región, así como de una sensibilidad particular de las izquierdas europeas por los movimientos revolucionarios de dicho continente. En particular el caso chileno, cuya política era más fácilmente comprensible y asimilable para los europeos que la de otros países, movilizó una importante solidaridad desde el golpe de Estado de 1973 (Moine, 2015). En contraste, el fenómeno del peronismo dificultaba la comprensión de la situación argentina, ya que no encontraban un equivalente válido en el panorama político europeo. No obstante, las dimensiones que cobraron las violaciones de los Derechos Humanos en dicho país sudamericano, provocaron una atención creciente sobre el mismo10. Sin lugar a dudas, tampoco es un dato menor que tres de los más activos de los 32 miembros del comité ejecutivo de la sede fundacional de París fueran exiliados argentinos: la abogada Liliana Andreone, quien trabajaba junto a Mnouchkine desde los albores de su exilio en Francia en 1976, su compañero y militante peronista Envar El Kadri y el reconocido cineasta político Fernando Solanas. Esta presencia argentina funcionó como un motor para denunciar las violaciones de Derechos Humanos en dicho país en particular, así como en los países vecinos, facilitando además los vínculos con personas y asociaciones latinoamericanas. Además de algunos casos puntuales adoptados por AIDA en sus inicios, una campaña más amplia titulada "Cien artistas argentinos desaparecidos" generó una importante repercusión en los distintos núcleos de la asociación. Iniciada en 1981, la campaña contó con una serie de acciones que apuntaban tanto a difundir datos concretos de lo que sucedía en Argentina como a manifestar su repudio en la vía pública, intentando sensibilizar a la ciudadanía europea a través de actos con una fuerte dimensión simbó- lica. Frente a la consternación por la larga lista de artistas desaparecidos enviada por la Comisión de Familiares de Desaparecidos y Presos por razones políticas de Buenos Aires, AIDA decidió, en vez de elegir un nombre en particular, tomar su conjunto como un caso colectivo para exigir que todos reaparecieran con vida11.

En ese marco fue publicado un libro colectivo llamado Argentine: Une culture interdite (Pièces à conviction 1976/1980) por la editorial Maspero12 de París y luego en español por la editorial Revolución de Madrid. Presentándolo como el intento de demostrar el plan sistemático de represión de una cultura popular e intelectual determinada, a la que el régimen juzgaba como peligrosa, Envar El Kadri y Liliana Andreone, bajo el pseudónimo de "Juan José Hernández Arregui", reunieron recortes de artículos de diarios argentinos y testimonios de artistas e intelectuales que desde el exilio describían la represión en los diferentescampos artísticos argentinos. El emotivo prólogo de Miguel Ángel Estrella y el epílogo reflexivo de Julio Cortázar, enmarcaron los relatos de personalidades como Mercedes Sosa, Eduardo Galeano, Alberto Adellach y Carlos Alberto Gabetta, que se referían a sus áreas profesionales, mientras que las ilustraciones de Ricardo Carpani, Hugo Pereyra e Ignacio Colombres graficaban la censura. En lo referido al cine, fue Fernando Solanas quien elaboró el informe respectivo, en el que denunciaba la censura, el asesinato de artistas y la opresión que vivían los argentinos. Allí, Solanas afirmaba que el cine producido en el país se encontraba vaciado de sentido y que, por lo tanto, sólo podía producirse en la resistencia y en el exilio13.

Además de la contra-información por distintos medios, la campaña por los artistas argentinos desaparecidos combinó el savoir-faire de distintos artistas para llegar emocionalmente a la opinión pública transnacional14. En las discusiones entre los miembros de AIDA se alegaba que el uso recurrente de la recolección de firmas había "devaluado" su impacto, por lo que debían pensar un proyecto de gran alcance con una perspectiva estética que fuera superadora de esa práctica15. La campaña "100 pintores para 100 artistas 'desaparecidos' en Argentina" consistió en solicitar la elaboración de 100 pinturas-estandartes representando el número de la lista de artistas desaparecidos confeccionada para la ocasión. Organizado por área de expresión, los nombres y fechas de desaparición de artistas funcionaban como ejemplo contundente de la represión cultural que sufría la Argentina16. Aunque se dio plena libertad a los participantes en la elección del motivo visual y la técnica, se solicitó que se expresaran sobre un lienzo de dos por tres metros, dispuesto de manera horizontal o vertical. AIDA solventaba los gastos de producción poniendo a disposición telas, enduído, pigmentos, barniz de protección y un espacio para elaborarlas (uno de los talleres de la Cartoucherie, la antigua fábrica de armamentos ocupada por la compañía de Ariane Mnouchkine en 1970)17. El criterio del tamaño apuntaba a darle una unidad a la diversidad estética de banderas que los artistas de distintos orígenes, corrientes y trayectorias elaboraron para esta causa. Perforada a lo largo de su extremo superior, cada pintura se exponía gracias un dispositivo diseñado por el escenógrafo del Soleil Guy-Claude François18: dos cañas de bambú atadas en forma de cruz de la que colgaba el lienzo, enhebrado por una cuerda que la sostenía a la caña horizontal. Además, una soga atada en cada uno de los dos extremos inferiores permitía que entre tres personas se sostuviera la bandera extendida. Un entrenamiento sobre el montaje del material y su transporte fue seguido 
de un ensayo en el parque de la Cartoucherie, de manera de asegurar que la manifestación fluyera sin sobresaltos generando el efecto estético y el impacto emocional buscados 19 .

La primera marcha pública de esta campaña se llevó a cabo el 12 de septiembre de 1981 en el centro de la ciudad de Ámsterdam, comenzando en la calle Waterloo Plein, a 200 metros de la casa-museo de Rembrandt (Rembrandthuis) y de la Ópera Nacional (Dutch National Opera \& Ballet). Este evento inaugural fue moderado en cuanto al número de concurrentes pero simbólicamente poderoso. Allí se probó el manejo de las pinturasbanderas, con unos quince ejemplares ya terminados que habían comenzado a realizarse desde junio. Además, cien personas desfilaron en fila india vestidas de negro, con una suerte de bolsa de arpillera en la cabeza20 (perforada a la altura de los ojos) y un cartel que indicaba uno de los nombres de las víctimas. Cada manifestante de la fila prestaba así su cuerpo para representar a aquellos de los que se desconocía su paradero, haciendo simbólicamente aparecer en el espacio público europeo a los artistas "desaparecidos" en Argentina. Para completar esta dimensión performativa del desfile, un camión los acompañaba haciendo sonar una campana como en un cortejo fúnebre, y así llamando a la solidaridad21. Durante el evento, también se escuchaban algunas melodías compuestas para esta ocasión tocadas por los músicos presentes22.

La mayor manifestación de la campaña se realizó en París el sábado 14 de noviembre de 1981 desde las 11 de la mañana. Tres días antes de la marcha, se publicó un anuncio en el diario Libération con algunas fotografías de las pinturas, informando del evento y solicitando la ayuda de 400 personas para llevar las banderas, distribuir volantes y pegar afiches. Para que el acontecimiento tuviera un mayor impacto visual, se invitaba a los manifestantes a vestirse de negro y a llevar un pañuelo blanco "como hacen las madres de la Plaza de Mayo todos los jueves en Buenos Aires"23. Así, un símbolo que había servido de bandera de este movimiento de repudio en Argentina, era adoptado en otras latitudes para acompañar su lucha24. Bajo la dirección de Ariane Mnouchkine, articulando el trabajo creativo de distintas personas, este acontecimiento apuntaba a "renovar la forma de acción contra la represión y por la libertad de creación y de expresión" 25.

Además de los cien pintores que elaboraron las banderas, también se requirió la participación de cien músicos que tocaron la melodía compuesta para esta ocasión por Gilbert Artman (compositor y fundador de la banda llamada Urban Sax).Además participaron los actores del théâtre du Soleil, varios fotógrafos (entre ellos Martine Frank, miembro fundador y fotógrafa oficial de dicha compañía, y su esposo, el célebre Henri Cartier-Bresson) así como cineastas -Fernando Solanas y Anne Barbey26- que filmaron la experiencia. Se calcula que un total de entre 5.000 y 7.000 personas participaron del acontecimiento27, con la presencia de algunas personalidades argentinas como Julio Cortázar y Miguel Ángel Estrella, junto a los actores Yves Montand y Simone Signoret, los cineastas Costa Gavras28 y Patrice Chéreau, los cantantes Jean Ferrat y Marcel Amont, los escritores Marek Halter y Hélène Cixous, entre otros. Además, el Ministro de Cultura Jack Lang y la Primera Dama Danielle Mitterrand, si bien no asistieron, enviaron sus respectivas cartas de apoyo29.

La presencia de los músicos no escapó a la minuciosa reflexión estética. Como lo indica su nombre, Urban Sax recurría a este tipo de prácticas en las se rompe la frontera con los espectadores irrumpiendo en el espacio público de la ciudad, en actos concebidos como performances. Surgido en 1973 con sólo 8 músicos, Urban Sax integró un número importante de saxos de toda la gama de esta familia (sopranos, altos, tenores y barítonos bajos) de manera de poder explotar la movilidad del instrumento para experimentar con el espacio y el desplazamiento del sonido en relación a un público que también se encontrara en movimiento30. Otro de los aspectos de exploración de Artman son los espirales polirítmicos, que apuntan a interrogar al público en una performance visual y sonora31. Así, la melodía compuesta para la marcha de AIDA es una música semirepetitiva, con piezas evolutivas de diferentes colores y tonos, que sería el sello musical de la marcha.

Paralelamente al estudio cuidadoso de Artman del uso del espacio urbano como soporte de la puesta en escena, que requería una preparación detallada de la dimensión espacial y coreográfica de sus intervenciones32, el desfile de manifestantes y banderas fue también concebido en un sentido estético. De hecho, el itinerario se analizó de la manera con la que se define el rodaje de una película, buscando las locaciones ideales para establecer el relato33. Su dimensión visual se compuso, por lo tanto,coordinando el movimiento de los músicos y el desplazamiento de las pinturas-banderas. La búsqueda estética y simbólica llevó a iniciar la marcha en el Panteón, aquel monumento nacional donde descansan los restos de grandes hombres de Francia, descender la rue Soufflot (calle que traza una diagonal desde dicho monumento hasta la rue Saint Michel y los jardines de Luxemburgo), pasar frente al teatro Odéon, luego atravesar el Pont Neuf, cruzando por la punta oeste de la isla de la Cité, bordear el Museo Louvre por la Rue de Rivoli, recorrer los jardines de Tullerías a lo largo hasta llegar a la última fuente previa a la plaza de la Concorde. Así, los manifestantes atravesaron el corazón de la ciudad, circulando frente a monumentos y espacios urbanos de gran fuerza simbólica vinculados al mundo de la cultura francesa y occidental. En dicho gesto, los organizadores apuntaban a traer a la agenda política un problema de un país periférico -Argentina-, intentando involucrar a los ciudadanos locales y de otros países industrializados en dicha causa.

El desfile estuvo encabezado por algunos músicos (saxos y tambores), un grupo de madres de Plaza de Mayo34 con su clásico pañuelo blanco sobre sus cabezas, acompañadas por las veinte pinturas-banderas más livianas. Entre ellas se encontraba en primer plano aquella en la que tres siluetas negras sin rostro35 aparecían junto a la pregunta: “¿Dónde están? / Où sont-ils ?"36. Por la dificultad del traslado del material, y por el efecto que generaba el incremento de la masa de manifestantes, se establecieron etapas a lo largo del itinerario en las que se irían sumando nuevos grupos a la marcha. Una vez alcanzado el destino, todas las pinturas-banderas desfilaron frente a la vista del público para ubicarse en dos niveles detrás del escenario preparado para la ocasión. De esa manera, se hacía uso de la "geografía" de los jardines para coreografiar la marcha: las 
banderas bordeaban la fuente, en un recorrido semicircular, y se aprovechaban las rampas y los balcones de los dos extremos de la plaza para ubicar las pinturas en exposición. Sobre el escenario se encontraba Alba González Souza tocando el bandoneón junto a la foto de identidad de su hijo desaparecido y el letrero "Où est mon fils? Rafael Lezama, uruguayen. Détenu et disparu le 1er octobre 1976 en Argentine"37. A los tangos de Alba, le siguieron los saxofonistas repitiendo la melodía de Artman y, finalmente, se cerró el acto con la lectura de cada uno de los 100 nombres de los artistas desaparecidos seguida de la pregunta del público: “¿Dónde están?"38. La manifestación-espectáculo culminó hacia las tres de la tarde, después de 4 horas en las que se expresó la solidaridad de una manera artística39. Esta creación colectiva fue, en definitiva, una puesta en escena fuertemente simbólica en la que la música y el silencio de la contemplación estética reemplazaron los discursos tradicional es para "tomar la palabra".

\section{El Exilio de Gardel. Relectura de una experiencia personal y colectiva}

Para pensar la manera en la que la búsqueda artística y la obra de Fernando Solanas fueron transformándose a través de los años, no puede soslayarse su particular trayectoria. "Pino" Solanas ya se había convertido en una figura con un considerable reconocimiento internacional cuando se refugió en París a los 40 años de edad. La Hora de los Hornos (1968), film que había realizado clandestinamente con Octavio Getino y Gerardo Vallejo bajo el nombre de Grupo Liberación, y sus escritos teóricos se había difundido ampliamente por círculos militantes del país, así como por encuentros y festivales en distintas latitudes, otorgándole no sólo una visibilidad sino también una red de contactos nada despreciable (Del Valle Dávila, 2014; Cristiá, 2016). Su intención de combinar creación con política se plasmó de manera expositiva y didáctica en las películas rodadas en Puerta de Hierro junto a Getino, llevando la palabra e imagen de Perón de España hacia Argentina en Revolución Justicialista y Actualización doctrinaria para la toma de poder (1971). Su postura militante en relación al peronismo, y su estricta defensa a pesar de las contradicciones de la tercera presidencia de Juan Domingo Perón, le habían costado tanto las críticas como la incomprensión de cineastas de otras latitudes. (Mestman, 2014)

Si Fernando Solanas había abordado el destierro previamente en su película Los Hijos de Fierro (1975) al tratar la proscripción del peronismo, la expulsión de su líder y la resistencia popular en una ficción altamente metafórica, en El Exilio de Gardel (1985, Argentina/ Francia, 118') dicha problemática se sitúa en el centro de la escena. El tema atraviesa la narración condensando distintas experiencias y climas emotivos, ya que el proyecto experimentó numerosas peripecias que dilataron su concreción. La obra se remonta al período previo a su propio exilio, cuando Solanas preparaba el rodaje de un film titulado -como el tema de Piazzola- Adiós Nonino. La trama original narraba la historia de un bandoneonista que emigraba de Rosario a Buenos Aires en busca de su identidad cultural. Tras el golpe militar de 1976, el rodaje debió ser suspendido con la salida del cineasta del país. El proyecto sufrió entonces modificaciones en el curso de los fallidos intentos de realización, pasando primero a titularse Los tangos de Homero, en alusión a Manzi, y luego L'exil de Gardel (Monteagudo, 1993).La nueva versión se centró en la vida cotidiana de un grupo de exiliados sudamericanos refugiados en París, con un tratamiento en ciertos momentos dramático y en otros de tinte cómico. Según Solanas, si el guión anterior a la última reescritura estaba totalmente teñido de la tristeza del desarraigo,tras las elecciones democráticas en Argentina y la posibilidad de retornar, la obra incorporó la alegría del regreso. Este distanciamiento permitió mirar con ternura y humor situaciones vividas trágicamente en el pasado,cuyas asperezas habían sido pulidas por el tiempo40.

Sin embargo, la realización del film se postergó también por toda una serie de inconvenientes, comenzando por el retiro de la compañía Gaumont de la producción por dificultades financieras, y del fallecimiento del director turco Yilmaz Güney, quien había prometido apoyar el proyecto41. Una vez concretada una co-producción oficial entre Francia y la Argentina democrática, el último importante obstáculo fue la renuncia, a poco de comenzar el rodaje, de la actriz española Charo López, quien fue remplazada por la francesa Marie Laforet en el rol protagónico42. El Exilio de Gardel se estrenó finalmente en el festival de Venecia en septiembre de 1985, obtuvo el Gran Premio especial del jurado, seguido de otros galardones que colaboraron a preparar el terreno para su estreno en Argentina. Mientras que la crítica española la relacionaba con Carmen (1983) de Carlos Saura por la fuerte presencia de la danza y la clasificaba como polémica43, el realizador temía la recepción que tendría la película en su tierra natal por abordar una problemática sensible en esos años44. En efecto, la reacción del público argentino ante la propuesta fue a veces prejuiciosa y crítica45.

Una vez redactado el libreto pero antes de su rodaje, Solanas comentó para el diario Clarín que la obra incluía "vivencias propias y una ficción de amor" (Clarín, octubre 1983). Si La Hora de los hornos (66-68) fue un "ensayo político" y Los Hijos de Fierro (72-74) un "poema épico", El Exilio de Gardel es definida por el director como "una ficción humana" que "refleja parte de lo que viví". El autor también explicaba que "el exilio aparece como una máquina de destrucción que puede llevar al desarraigo, cual estado de depresión a nivel de la muerte". El periodista argentino que lo entrevistaba agregó que sería asimismo la "tácita reflexión de que el exilio recorre como un fantasma castrador toda la historia nacional". De hecho, la referencia al exilio de José de San Martín en Francia es crucial, por lo que también se filmó en Boulogne-sur-Mer, en el escenario en el que el "Libertador" vivió sus últimos días. Como en este caso, la elección de las locaciones parece acompañar tanto la búsqueda estética como la referencia a escenarios del exilio argentino en Francia: variados exteriores en París (Champs Elysées, Versailles, la isla Saint-Louis, la vista desde las escaleras del Pompidou, la Gare de l'Est) y algunos 
interiores típicos como el aeropuerto Charles de Gaulle, que se completaron con variados interiores de Buenos Aires.

La narradora de la historia de El Exilio de Gardel es María, protagonizada por Gabriela Toscano, una joven argentina de 20 años que acompañó a su madre en el exilio en Francia tras el secuestro y desaparición de su padre. Desde la mirada de María, el espectador descubre las desventuras de su madre Mariana, quien junto a un grupo de artistas latinoamericanos intentan culminar un espectáculo con el nombre de la película. Los autores de la obra inacabada son dos: Juan Uno que escribe desde Buenos Aires y Juan Dos46, un bandoneonista y director de la obra musical radicado en París, quien mantiene una relación amorosa con Mariana. Situada temporalmente a fines de 1979 y principios de 1980, la narración transcurre entre los conflictos intersubjetivos, intergeneracionales y colectivos de esta comunidad de artistas exiliados. El espectáculo musical que se encuentran produciendo cuenta la propia historia de desarraigo y de la resistencia tanto desde dentro del país a través del personaje ausente (Juan Uno) como desde el exilio (Juan Dos). El tango aparece entonces como representante de la cultura argentina y así como otro protagonista del film.

De manera similar a La Hora de los Hornos, esta ficción se estructura con intertítulos que ritman la obra. Se trata de "Historias convertidas en ficción" como cantan las jóvenes mientras despliegan una coreografía de danza jazz sobre una terraza parisina en una escena de transición hacia la cuarta parte del film. En líneas generales, la película transmite dos emociones eminentes, el desgarramiento del destierro y una alegría de vivir que se impone en la música y danza de los artistas, así como en el humor de ciertas escenas. Aparecen allí las contradicciones de la experiencia subjetiva, signada por el dolor del destierro pero movilizada por la pulsión de vida. La "tanguedia" sería entonces esa mezcla de "tango, tragedia y comedia" que la película combina, un espectáculo-cocktail de música y danza que yuxtapone una "cosmogonía" cultural argentina con la herida del exilio político, una cuota surreal y cierta comicidad del absurdo.

Como lo señala Jensen, la película de Solanas:

(...) manifiesta su apuesta por la democracia, la tolerancia, la lucha por los derechos humanos, que lo habían comprometido activamente en su destierro francés y lo distanciaban de la opción política de aquel otro Solanas que a finales de los años sesenta y principios de los setenta levantaba las banderas del peronismo de izquierda, el antiimperialismo y la auténtica democracia de una sociedad sin clases. (2005, p. 196)

En efecto, en el argumento del film, aparecen referencias claras y rastros de la experiencia de AIDA. La primera referencia transcurre cuando María relata su participación regular junto su madre,en un comité de solidaridad que se reúne todos los sábados. Allí,un grupo de exiliados y algunos franceses ligados al mundo del espectáculo discuten tácticas y estrategias de acción en un "teatro de las afueras de París". Aunque no mencionan su nombre, las imágenes del exterior y del debate desatado en el interior fueron filmadas precisamente en La Cartoucherie. Cuando la cámara toma en el fondo los portones rojos característicos de ese espacio, se identifica el ámbito en el que efectivamente se llevaron a cabo muchas de las reuniones de AIDA, precisamente los días sábado, así como otras reuniones de exiliados argentinos 47.

En la película, Philippe Léotard, uno de los actores fundadores del Théâtre du Soleil con Ariane Mnouchkine48, personifica a Pierre, el director de teatro que aceptará dirigir la "tanguedia" cuando Ángel (protagonizado por el mismo Solanas) abandona la obra por la ausencia de final del espectáculo. Pierre, cuyo rol se asemeja al de Mnouchkine en AIDA, es el orador principal de la reunión. En el centro de una escena donde se atisban pinturasbanderas y maniquíes sin miembros dispuestos como en una escenografía teatral de fondo azulino, Pierre plantea exasperado el problema que impulsó AIDA: la necesidad de implicar a la población local creando un lenguaje nuevo para interpelarlo. Pierre, de pie frente al resto de los participantes sentados en semicírculo, afirma:

La gente está saturada de mensajes. Los petitorios no funcionan más.(...) La gente ya no responde cuando la llamamos. No hay nadie aquí. [Y mirando al fondo de la sala, agrega:]Gracias Jean-Marie, gracias Florence, afortunadamente ustedes vinieron. Hay que hacer algo todos juntos y hablar a la gente en un lenguaje nuevo49.

Ante la pregunta de una mujer del público sobre si le parece que con los maniquíes funcionará, el director responde afirmativamente, insistiendo en la necesidad de una innovación creativa. Los dos participantes franceses toman sucesivamente la palabra manifestando sus posiciones y, en particular, Jean-Marie parece repetir reflexiones de esos años cuando expresa una serie de preguntas retóricas: “¿por qué el público no se siente concernido, por qué se perdió el interés, la pasión, por qué nos transformamos en seres amorfos, por qué no nos cuestionamos, por qué estamos refugiados en un egoísmo que nos lleva a la muerte?"

Si la película menciona la coexistencia de unos 400 comités de solidaridad a lo largo de Francia en ese entonces, también se ocupa de representarla manera en la que éstos colaboraron. En la ficción, un comité apoya el viaje a Argentina de la señora Alcira (esposa de Gerardo, un escritor amigo del papá de María), cuya hija y nieta se encontraban desaparecidas (Marta y Martita)50. Gracias a ese caso, se remarca la colaboración con diferentes organismos internacionales, quienes les brindaban protección para poder realizar el viaje. Mientras que los jóvenes cantan sobre la solidaridad internacional resumiendo el drama de la obra y deslizando una crítica respecto ala contradicción que asumen los países centrales en este contexto ["Historias convertidas en ficción, por toda su dolida humanidad. Europa dio la solidaridad, sincera o por culpabilidad. El Norte fue también complicidad, del Este hasta el Oeste soledad" (min. 95-97)], la cámara registra una serie de 
pinturasbanderas reunidas en el taller de La Cartoucherie, la preparación del material para la marcha donde aparece Envar El Kadri levantando una de las banderas. A dichas imágenes se intercalan otras del regreso de Alcira de su viaje a Buenos Aires, mientras que se impone la voz en off de Alcira relatándolas impresiones de ese viaje, su miedo de encontrarse sola, y la alegría de que hallar otras madres y abuelas esperándola: "Me di cuenta que había mucha gente que hacía tiempo que estaba luchando por lo mismo que yo, y eso me dio nuevas esperanzas" afirma el personaje.

Apenas culmina su relato, se desliza la melodía de saxos compuesta por Gilbert Artman para la marcha de París mientras que se proyectan imágenes reales de ese desfile: el momento en el que cruza el Pont Neuf, el avance de los manifestantes con el fondo del Panteón y la concentración final en Tullerías. En la selección de las imágenes, Solanas decidió dejar claramente visible la bandera de AIDA en los tres momentos representados de la marcha. Más allá de los escenarios descritos, el cineasta también incorporó protagonistas reales de la historia del exilio latinoamericano. Así como en Los Hijos de Fierro incluyó en la ficción a Julio Troxler, el sobreviviente del fusilamiento de León Suárez finalmente asesinato por la Triple A durante el período de rodaje de ese film51,otros protagonistas son incluidos en esta nueva ficción. De hecho, en la primera fila de las imágenes reconstruidas de la manifestación aparece Alba González Souza. La pianista uruguaya marcha con un pañuelo blanco sobre la cabeza y lleva consigo el mismo cartel con el que denunciaba la desaparición de su hijo mientras tocaba el bandoneón en el escenario montado por AIDA en 198152. Entre las imágenes de la manifestación se superponen, como si ocurriera durante la marcha, el anuncio del nacimiento de la primera hija de dos personajes de la ficción (el negro y Susana), a la que llamaron Victoria (como Solanas había llamado a su propia hija). "El acto más hermoso por la vida que hemos realizado", anunciaba el alegre padre, extendiendo metafóricamente ese nacimiento a la nueva etapa en la que se embarcaba la Argentina.

La película está claramente inspirada en el teatro53, y seguramente la experiencia de Solanas en AIDA contribuye a esta influencia en la estética del film. Sin embargo, no existe un intento de reproducción de ese pasado, sino una reelaboración en donde el recuerdo se transforma, como todo trabajo de memoria (Jelin, 2002). Cuando en la ficción se realiza una marcha, Solanas integra parte de las imágenes capturadas por él el 14 de noviembre de 1981, junto con otras que rodó posteriormente para reconstruir el evento con los actores del film. En la secuencia ficcional de la marcha, además de los actores protagónicos y de Alba, se identifican la hija del director, Victoria Solanas, así como el hijo adolescente del artista plástico Luis Felipe Noé exiliado en París, el actualmente reconocido cineasta Gaspar Noé. En dicha secuencia se agregaron elementos que no pertenecen a la experiencia real de 1981, principalmente la incorporación de un camión que circula por el centro de la marcha llevando falsos cuerpos sin vida construidos con bolsas de arpillera y soga. Este elemento de fuerte impacto, que alude a la tortura y al asesinato, pareciera ser una condensación de lo acontecido en las marchas de AIDA de Ámsterdam y de París que hemos relatado anteriormente.

Entre los participantes del film también figura el hijo de Fernando Solanas y actual director de cine, Juan Solanas, como pasante en la realización del film, así como el violinista Emilio Cedrón, hijo del músico argentino Juan "Tata" Cedrón radicado en París desde principios de los setenta54. Así se pone en evidencia la experiencia de esta segunda generación tanto en la elección del narrador como en su participación en distintos roles. Aunque Solanas hable de su propia historia y la de sus pares, también le otorga un protagonismo compartido a la generación joven. Vale señalar que uno de los capítulos del film -así como uno de los tangos compuestos para la obra55- se titula "Los hijos del exilio". Asimismo, la última palabra de la película se la concede a María, quien refiere al sentido de "volver" para esa generación cuya identidad se encuentra partida entre dos países: el de sus padres y el de adopción56.

\section{Conclusión o cómo rememorar desde el presente, entre ficción y fuente histórica}

La breve arqueología de la película El Exilio de Gardel y el análisis de algunas escenas permiten identificar esas distintas sedimentaciones emotivas y vivenciales que se superponen en el producto final. Fruto de las sucesivas reescrituras que sufrió el guión y de sus derivas, la película parece cristalizar un trabajo de memoria que es siempre móvil y cambiante. El presente artículo intentó, en consecuencia, reconstruir históricamente una experiencia a partir de diversas fuentes y, a su vez, identificar la reelaboración que significó la producción del film. Se trata de una película que entreteje ficción y recuerdos del pasado reciente, reelaborados desde un presente y en una búsqueda estética innegable. Pero, a pesar de ello, también es un documento histórico, pues permite al historiador conocer y reconocer una experiencia de la que sobreviven pocas huellas. Se trata de una corriente particular del movimiento de defensa de los Derechos Humanos, cuya actividad se intensificó a fines de los setenta y principios de los ochenta, y que derivó, en el caso de algunas personas vinculadas a la práctica artística, en la Asociación de Defensa de Artistas Víctimas de la Represión en el Mundo. Además de sus miembros, entre los cuales se encontraba Fernando Solanas, AIDA se nutrió de la solidaridad de numerosas personas que, sin ser necesariamente parte de la misma, colaboraron por diversas causas.

En lo relativo a la campaña por los desaparecidos en Argentina, esta película, junto a otros documentos, permiten salvaguardar las imágenes de obras cuyo paradero es desconocido. Si según ciertos testimonios recogidos, algunas de las pinturas-banderas realizadas para las manifestaciones de AIDA habrían sido vendidas para recaudar fondos para la causa57, otras fueron enviadas a Argentina en diciembre de 1983. Trasladadas en el avión oficial de la delegación del gobierno francés a cargo del Primer Ministro Pierre Mauroy, quien asistió al traspaso de mando a las nuevas autoridades democráticas, las pinturas debían ser entregadas a las Madres de Plaza de Mayo58. Se presume que fueron utilizadas en algunas manifestaciones de los albores de la nueva 
etapa democrática59 y quizás descansan aún hoy en algún depósito de dicha asociación argentina, sino fueron víctimas fatales de la humedad y del tiempo, además del olvido. El Exilio de Gardel, sin proponérselo, colabora a inmortalizar esas imágenes como algunos otros registros de esa mítica marcha parisina.

\section{Notas}

1. Serniès, H. (17/07/1979) "Campagne pour la défense des artistes victimes des dictatures", Le Matin de Paris, Curzi, L. (17/07/1979) "Mnouchkine et Lelouch témoignent. Au Chili on tue les gens de l'intérieur", L'Humanité. 2. "La Peau de chagrin" fue el título de una novela de Honoré de Balzac de 1831. La misma trataba de un joven que recibió una piel de zapa o cuero mágico que le permitía satisfacer sus deseos pero que se encogía con cada uno de ellos. Desde entonces la expresión se utiliza para designar aquello que se reduce inevitablemente por el uso. Mnouchkine, A. y Lelouch, C., (21/12/1979) "La liberté est comme une peau de chagrin", Le Monde.

3. Ídem.

4. Récépissé de la Préfecture de Paris, 03/12/1979, Archivo particular de Jean-François Labouverie.

5. 6, rue de l'Eure (sous-sol), 75014 Paris.

6. Cuando utilizamos esta definición hacemos referencia a una ampliación del concepto de esfera pública de Jürgen Habermas, con la que el teórico alemán denomina el ámbito comunicativo donde se gesta la opinión pública, y donde ésta puede expresarse como fuerza política ciudadana tanto en contraposición a los poderes privados como presionando al Estado. En nuestro mundo globalizado, las pujas de poder entre diferentes actores (nacionales y transnacionales) con los estados-nación se encuentran sujetos a un control ciudadano transnacional, fenómeno teorizado por Nancy Fraser en el trabajo mencionado.

7. Debemos aclarar que no se pretendía limitar la acción a dichos países. Por el contrario, se proyectaba crear AIDAs en otros países como Colombia, Perú y Polonia. Cf. Cuaderno de Actas de AIDA, Archivos de AIDA. 8. Término utilizado por la asociación para hacer referencia al uso de recursos artísticos en una manifestación pública.

9. Dossier "L'Argentine: 100 artistes disparus / Argentina: 100 artists disappeared" (12/1982), AIDA international, p. 1.

10. Como es sabido, el Mundial de Fútbol de 1978 convocó la preocupación internacional y multiplicó las iniciativas en distintos puntos del planeta. Respecto a Francia, consultar Franco (2008).

11. Volante "L'Argentine: 100 artistes disparus" (1981), AIDA.

12. Se trata de la editorial de François Maspero, una las grandes difusoras de textos contestatarios en los años sesenta y setenta. Este intelectual poseía una librería muy reconocida llamada "La joie de lire", donde se reunían intelectuales de distintas latitudes. Su editorial pasó a ser dirigida por François Gèze en 1982, adoptando el nombre de La Découverte desde el año siguiente. Sobre dicho editor, en relación a otros dos en Italia y Alemania, consultar: Hage, 2010.

13. AIDA, Argentine: une culture interdite. Pièces à conviction (1976-1981), Paris, Maspero, 1981, p. 109. 14. Por cuestiones de espacio no abordamos aquí las manifestaciones de la campaña en Alemania, que fueron previas a las abordadas. "Shcrei wo du kannst, Argentina", AIDA Bundesrepublik Deutschland e. V., (1981). También posteriormente repercutió en otras ciudades como Dijon, Grenoble y Ginebra Washington Cf. Les trois objectifs de l'AIDA" (03/02/1982), La Tribune de Genève; Hall, C. (12/02/1982) “Artist \&", Washington Post. 15. Entrevista con Liliana Andreone, Buenos Aires, 25/06/2016.

16. Carta convocando la colaboración de pintores bajo el título "100 pintores para 100 artistas 'desaparecidos' en Argentina desde el Golpe de Estado de 1976" (10/1981), AIDA, Paris.

17. Ídem.

18. (1941/2014) Diseñó la escenografía del Soleil desde L'âge d'or en 1975 hasta Le Dernier Caravansérail en 2003.

19. Algunas fotos del ensayo en el parque la Cartoucherie y otras captadas en el galpón que el Soleil concedió para la elaboración y guardado de las pinturas aparecen en la convocatoria a la marcha publicada unos días antes en el diario Libération. Fotografías de David Boeno, Torregano Collectif Presse, Libération, 11/11/1981. 20. El objeto elegido para cubrir los rostros, además de borrar la identidad del actor que prestaba su cuerpo, probablemente buscaba hacer referencia a los métodos de tortura.

21. Fotografía aérea de Gerda Van Veen, publicada en el folleto "L’Argentine: 100 artistes disparus" (1982), édition AIDA international, p. 9.

22. Descripción de la campaña redactada por Envar El Kadri (firmada con el pseudónimo Cachò) y publicada en Testimonio Latinoamericano. Dicha revista, editada en Barcelona por Álvaro Abós y Hugo Chumbita, reproducía textos enviados por exiliados radicados en distintos países. El Kardri, E. (12/1981) "Cien banderas por cien artistas", Testimonio Latinoamericano, $N^{\circ} 11$, p. 33. Más allá de esta marcha, la campaña en Holanda también contó con la elaboración de una docena de postales con imágenes de diferentes artistas. Postales conservadas en el archivo AIDA de la Cartoucherie.

23. Convocatoria de AIDA para la marcha, Libération, 11/11/1981.

24. Sobre el surgimiento de este símbolo como modo de identificación, cohesión y manera de hacerse visibles en el espacio público (Gorini, 2006, p. 117/119) y sobre diferentes aspectos de la dimensión visual del movimiento de Derechos Humanos que fue gestando en Argentina (Longoni, 2010, p. 35-57).

25. Convocatoria de AIDA, op. cit. 
26. Esta dramaturga y directora de teatro, elaboró un documental de 11 minutos sobre la experiencia que se titula “¿Dónde están?”, disponible en la Biblioteca Nacional de Francia, en París. Este documento tenía aparentemente sólo una función de registro y no habría sido difundido por ningún circuito. Entrevista telefónica a Anne Barbey, 06/06/2016.

27. La primera cifra es la que difundió la agencia de prensa estadounidense Associeted Press, según aparece en el artículo publicado en el diario La Nación en Argentina ("París: Marcha por los desaparecidos", La Nación, 15/11/1981, p. 4). Mientras que el dossier editado por AIDA Holanda en 1982 reproduce ese mismo número (Dossier "L'Argentine: 100 artistes disparus...", op. cit. p. 10), "Cacho" El Kadri estima la presencia de 7.000 manifestantes (cf. "Cien banderas por cien artistas", op. cit.).

28. Si bien no era oficialmente miembro activo de la asociación, Kostantinos Costa Gavras participó, por ejemplo, de la difusión televisiva del evento en "Journal", Antenne 2, 13/11/1981. URL:

https://www.ina.fr/video/I05244601

29. La carta de Jack Lang, en la que además se compromete a recibir artistas que se encontraran en situación de solicitar asilo en Francia, fue reproducida en la última página del dossier de información realizado en Holanda. Dossier "L'Argentine: 100 artistes disparus...", op. cit. p. 32.

30. Para más información e imágenes, consultar el sitio oficial de la banda, la cual que se encuentra aún en actividad: http://urbansax.com/

31. En tanto esa melodía se toca en manifestaciones colectivas, a menudo en celebraciones públicas, la música recobraba su función ritual. La dimensión visual de la banda se completa con un vestuario particular, que generalmente es un overol blanco, que uniformiza, despersonaliza a los saxofonistas y los disuelve en un cuerpo colectivo. Esa búsqueda experimental explica que Urban Sax haya realizado conciertos con amerindios de Vancouver, con bailarines javaneses en Yakarta o músicos sufíes en Turquía. Cf. "Gilbert Artman \& Urban Sax", (Patterson, 2013, p. 32/39).

32. Por ejemplo, en febrero de ese año -meses antes de su participación en la marcha de París- Urban Sax había intervenido el Carnaval de Venecia, por lo que incluyeron máscaras blancas en su vestuario. Cf. “Inform'elles", Marie-Ange Poyet \& Bénédicte Delesalle, Urban Sax à Venise (1981, 10'33"), disponible en URL: https://www.youtube.com/ watch?v=WxH3F6WGLjk

33. De esta tarea se encargaron algunos actores del Soleil, como Antoine Del Pin y JeanBaptiste Aubertin, que recorrieron la zona para definir el itinerario. (Cf. Entrevista telefó- nica con Antoine Del Pin, 09/06/2016). 34. Según el artículo del diario La Nación, dos madres habría viajado para participar de este evento. Cf. "París: Marcha por los desaparecidos", op. cit.

35. Tal vez fue esta tela una inspiración que habría impulsado a El Kadri a sugerir la idea de las siluetas en Argentina, según los testimonios reunidos por Longoni y Bruzzone (2008, p. 14), que le atribuyen a él ese impulso.

36. Relato de El Kadri en "Cien banderas por cien artistas", op. cit.

37. Esta práctica de recurrir una foto de identidad y constituir una pancarta junto a la fecha de desaparición y el vínculo que lo unía a dicha persona era utilizada en Argentina, primero de una manera espontánea en el recorrido de los familiares por cárceles y hospitales, luego sistematizada. Cf. Longoni, 2010, p. 5-17; Catela 2009, p. 337-361.

38. Registrado en la película “¿Dónde están?" de Anne Barbey. Algunos testimonios describen la gran emoción provocada por la belleza estética y el trabajo conjunto, como lo relata María Teresa Costantín. Videoinstalación "Memorias del exilio" (María Bagnat, Argentina, 2014), disponible en: https://www.youtube.com/watch? $\mathrm{v}=8 \mathrm{~h} 2 \mathrm{oNWj2rVo}$

39. En "Cien banderas por cien artistas", art. Cit.

40. Discurso de Fernando Solanas en el Instituto Lumière de Lyon, (14/11/2013). URL: https://www.youtube.com/watch?v=_4ZNFKfRLYo

41. En tanto el cineasta de origen kurdo se había visto obligado de partir de Turquía por razones políticas, en la conferencia de prensa de la firma de contrato se planteaba que la película podía "contarse como una historia de solidaridad, la del encuentro de dos cineastas, Solanas y Güney que además de otras constantes ejemplifican la evidencia de que el exilio es un tema universal", "Solanas y Gardel después del exilio" (08/10/1983), Clarín,

Sección "Espectáculos", p. 1 y 2.

42. Cómo se hizo El exilio de Gardel (Fernando Martín Peña y Alberto Ponce, Argentina, 2010, 85 min).

43. Marti, O. (29/08/1985) "Tangos, el exilio de Gardel muestra la vitalidad argentina”, El País.

44. "Solanas: exilio y "tanguedia" (19/12/1985), Clarín.

45. Cómo se hizo El exilio... op. cit.

46. El uso de este nombre de pila reitera el procedimiento de otros productos culturales. Por ejemplo, en El Familiar de Octavio Getino de 1972, los tres hermanos protagonistas se llaman Juan Pampa, Juan Atahualpa y Juan Tupac. (Tal 2005, Cristiá 2016).

47. Entrevista con Liliana Andreone, París, 28/04/2016.

48. Otro pequeño homenaje al Soleil y a Mnouchkine aparece tímidamente en el hecho de que en la casa de Mariana esté colgado el afiche de "Molière", obra que se estrenó en 1978.

49. Nuestra traducción del discurso en francés. Sin embargo, los subtítulos en español precisan "hagamos un esfuerzo de imaginación".

50. Probablemente hace referencia a Marta Vásquez, presidenta de las Madres de Plaza de Mayo línea fundadora y madre de María Marta, detenida-desaparecida en 1976 junto a su marido César Lugones. 
51. Troxler aparecía ya en La Hora de los Hornos, pero en ese caso brindando su testimonio sobre los hechos desde el mismo lugar en que habían ocurrido.

52. En el elenco, aunque en un personaje menor, figura también el actor y director chileno Óscar Castro.

Miembro del teatro Aleph, Castro sufrió dos años de prisión, la desaparición de su madre y su cuñado. En 1976, gracias a la solidaridad internacional, fue exiliado en París y, desde su creación, colaboró fuertemente con AIDA.

53. Así lo confirmó el mismo Solanas en la entrevista realizada por Fernando Martín Peña para el Making-of del film, manifestando que incluye convenciones teatrales. (Cómo se hizo El exilio... op. cit.).

54. También artistas radicados en París, sus hermanos eran Alberto, artista plástico, y Jorge Cedrón, cineasta asesinado en circunstancias sospechosas cerca de París en 1980.

55. Compuesto por José Luis Castiñeira de Dios, con letra de Fernando Solanas.

56. En 2006, se creó el colectivo "Hijos e Hijas del Exilio" cuya carta abierta manifestaba la voluntad de ser reconocidos como víctimas del terrorismo de Estado. Al haberse podido condenar a culpables de los casos de mayor gravedad de desaparición o muerte, consideraban que era hora de ocuparse de los suyos. En efecto, la Justicia comenzó a reconocerlos como tales algunos años más tarde. Consultar: "Para los hijos del exilio" (25/07/2015), Página 12, URL: https://www.pagina12.com.ar/diario/elpais/1-277868-2015-07-25.html

57. Entrevista con Odile Cointepas, París, 07/06/2016.

58. Entrevista telefónica con Liliana Andreone, 02/08/2016.

59. Por ejemplo, una fotografía de 1983 demuestra que se expuso una de las principales banderas de AIDA (de tres siluetas sin rostro con el texto "Dónde están?/où sontils?") junto a otras dos con figuras humanas realizadas en París, en torno a la pirámide de mayo. Archivo Roberto Amigo / Cedinci, 1983, URL: http://archivosenuso.org/ddhh/ lugar\#buenos_aires=\&viewer=/viewer/557\%3Fas_overlay\%3Dtrue\&js=

\section{Bibliografía}

Buch, E. (2016). Música, dictadura, resistencia. La orquesta de París en Buenos Aires, 1980. Buenos Aires: FCE.

Bruzzone, G. y Longoni, A. (dir.) (2008). El siluetazo. Buenos Aires: Adriana Hidalgo Editora.

Catela, L.(2009). "Lo invisible revelado. El uso de fotografías como (re) presentación de la desaparición de personas en Argentina", en Feld, C. y Stites Mor, J. (Comp.), El pasado que miramos. Buenos Aires: Paidós, p. 337-361.

Cristiá, M. (2016). Imaginaire péroniste. Esthétique d'un discours politique. Rennes: Presses Universitaires de Rennes.

Del Valle Dávila, I. (2015). Le nouveau cinéma latino-américain (1960-1974). Rennes: Presses Universitaires de Rennes. Franco, M. (2008). El exilio. Argentinos en Francia durante la dictadura. Buenos Aires: Siglo XXI.

Fraser, N. et al.(2014). Transnacionalizing the Public Sphere. Cambridge: Polity Press.

Gorini, U. (2006). La rebelión de las Madres, tomo 1. Buenos Aires: Norma.

Hage, J. (2010). Feltrinelli, Maspero, Wagenbach: une nouvelle génération d'éditeurs politiques d'extrême gauche en Europe occidentale, 1955-1982. Histoire comparée, histoire croisée, Tesis de Doctorado dirigida por M. Jean-Yves Mollier, Université de Versailles - SaintQuentin-en-Yvelines.

Jensen, S. (2005). "Del viaje no deseado al viaje de retorno. Representaciones del exilio en Libro de Navíos y Borrascas y Tangos. El exilio de Gardel”, en Jelin, E. y Longoni, A. (comp.), Escrituras, imágenes y escenarios ante la represión. Buenos Aires: Siglo XXI editores, p. 167-202.

Jelin, E. (2002). Los trabajos de la memoria. Buenos Aires: Siglo XXI Editores.

Longoni, A. (2010). "Fotos y siluetas: dos estrategias en la representación de los desaparecidos", en Crenzel, E. (comp.), Los desaparecidos en la Argentina. Memorias, representaciones e ideas (1983-2008), Buenos Aires:

Biblos.

Longoni, A. (2010). "Fotos y siluetas: políticas visuales en el movimiento de derechos humanos en Argentina", Afterall journal, p. 5-17.

Mestman, M. (Ed.) (2014). Estados generales del Tercer Cine. Los documentos de Montreal. 1974. Buenos Aires: Prometeo / REHIME n³, año 3.

Moine, C.n(2015). "Votre combat est le nôtre". Les mouvements de solidarité internationale avec le Chili dans l'Europe de la Guerre froide, Monde(s), vol. 2, n 8, p. 83-104.

Monteagudo, L. (1993). Fernando Solanas. Buenos Aires: CEAL.

Patterson, A. (2013). Music \& Second Culture Post Millennium. Portland: Eurock.

Stites Mor, J. (2012). Transition Cinema: Political Filmmaking and the Argentine Left since 1968. Pittsburgh: University of Pittsburgh Press.

Stites Mor, J. (ed.) (2013). Human Rights and Transnational Solidarity in Cold War Latin America. Madison: University of Wiscosin Press.

Abstract: In October 1979, a group of French and foreign artists and intellectuals headed by theater director Ariane Mnouchkine created AIDA (Association Internationale de défense des artistes victimes de la répression dans le monde), with the aim of denouncing censorship and violations of Human Rights of artists in different countries. The Association proposed creative actions, in order to exert international pressure on the victimization regimes. Founded in Paris, AIDA was deployed in several french cities, in other european countries and in the 
United States, using member networks to articulate actions. The case of the repression of the Argentine dictatorship deserved an important campaign of repudiation, boosted by the presence of some argentine exiles in the executive committee of the association. Under the title One hundred argentine artists who disappeared, a series of demonstrations of solidarity were coordinated in different cities, including marches, paintings and postcards, as well as a book on cultural repression in Argentina published in Paris, and shortly afterwards in Madrid. The biggest manifestation of AIDA of this campaign, a particular march in Paris on November 14, 1981, was filmed, among others, by argentine filmmaker Fernando Solanas, an active member of the Association. The experience of exile, and of AIDA in particular, appear as raw material of his fiction film The Exile of Gardel (El Exilio de Gardel, 1985), as well as the images captured on that day are incorporated into the film. Based on little explored archives (written and visual documents, correspondence), press and interviews, this article will try to outline the action taken by AIDA and analyze the way in which Fernando Solanas built his work reelaborating the memory of his experience in the Association. The study of this film will allow to collaborate, from an empirical analysis, to the reflection and theorization on the function of creation as a space of resistance, of action in the transnational public sphere and of memory of personal and collective life experiences.

Key words: international solidarity - transnational history - exile - artists - Human Rights - The Exile of Gardel.

Resumo: Em outubro de 1979, um grupo de artistas e intelectuais franceses e estrangeiros encabeçados pela diretora de teatro Ariane Mnouchkine criaram AIDA (Association internationale de défense des artistes victimes de la répression dans le monde), com o objetivo de denunciar a censura e as violações aos Direitos Humanos de artistas em diferentes países. A associação proponha ações criativas, de modo de exercer pressão internacional sobre os regímenes homicidas. Fundada em Paris, AIDA se expandiu a outras cidades francesas, a outros países europeus e aos Estados Unidos, usando as redes de contatos dos membros para articular ações. O caso da repressão da ditadura argentina mereceu uma importante campanha de repudio, potenciada pela presencia de alguns exiliados argentinos no comité executivo da associação. Com o título "Cem artistas argentinos desaparecidos" se coordenaram manifestações de solidariedade em diferentes cidades que incluíram marchas, elaboração de pinturas e postais, como também de um livro sobre a repressão cultural na Argentina publicado em Paris, e pouco tempo depois em Madri.

A maior manifestação de AIDA desta campanha, uma particular marcha feita em Paris o dia 14 de novembro de 1981, foi filmada, entre outros, por Fernando Solanas, membro ativo da associação. A experiência do exílio e da AIDA em particular, aparecem como matéria prima do seu filme O exílio de Gardel (1985), assim como as imagens capturadas naquele dia são incorporadas às rodadas para o filme. Sustentado em arquivos pouco explorados (documentos escritos e visuais, correspondências), prensa e entrevistas, este artigo procurará delimitar a ação feita por AIDA e analisar o modo em que Fernando Solanas fez sua obra reelaborando a memória da sua experiência na associação. O estudo deste filme permitirá colaborar, apartir de uma análise empírica, à reflexão e teorização sobre a fun- ção da criação como espaço de resistência, de ação na esfera pública transnacional e de memória de experiências vitais pessoais e coletivas.

Palavras chave: solidariedade internacional - historia transnacional - exílio - artistas - Direitos Humanos - O exílio de Gardel.

Frente el autoritarismo,la creación. La experiencia de AIDA y su relectura en el film El Exilio de Gardel (Fernando Solanas, Francia /Argentina, 1985) fue publicado de la página 75 a página92 en Cuadernos del Centro de Estudios de Diseño y Comunicación № 68 